\title{
Compendium of Single Event Effects for Candidate Spacecraft Electronics for NASA
}

\author{
Martha V. O'Bryan, Kenneth A. LaBel, Jonathan A. Pellish, Jean-Marie Lauenstein, Dakai Chen, Cheryl J. Marshall, \\ Megan C. Casey, Robert A. Gigliuto, Anthony B. Sanders, Timothy R. Oldham, Hak S. Kim, Anthony M. Phan, \\ Melanie D. Berg, Paul W. Marshall, Raymond L. Ladbury, Ted Wilcox, Alvin J. Boutte, Paul L. Musil and
}

Greg A. Overend

\begin{abstract}
We present the results of single event effects (SEE) testing and analysis investigating the effects of radiation on electronics. This paper is a summary of test results.
\end{abstract}

Index Terms-Single event effects, spacecraft electronics, digital, linear bipolar, and hybrid devices.

\section{INTRODUCTION}

The performance of electronic devices in a space radiation environment is often limited by its susceptibility to SEE. Interpreting the results of SEE testing of complex devices is quite difficult. Given the rapidly changing nature of both technology and the related SEE issues being discovered, SEE test data are very application specific and adequate understanding of the test conditions is critical [1].

Given this limitation of test data (application-specific), studies discussed herein were undertaken to establish the sensitivities of candidate spacecraft electronics as well as new electronic devices to heavy ion and proton-induced single event upset (SEU), single event latchup (SEL), and single event transients (SET). For total ionizing dose (TID) and displacement damage (DD) results, see a companion paper submitted to the 2012 IEEE NSREC Radiation Effects Data Workshop entitled: "Compendium of Total Ionizing Dose and Displacement Damage for Candidate Spacecraft Electronics for NASA" by D. Cochran, et al. [2].

This work was, supported in part by the NASA Electronic Parts and Packaging Program (NEPP), NASA Flight Projects, and the Defense Threat Reduction Agency (DTRA) under IACRO\# 11-4395I.

Martha V. O'Bryan is with MEI Technologies Inc., work performed for NASA Goddard Space Flight Center (GSFC), Code 561.4, Bldg. 22, Rm. 062A, Greenbelt, MD 20771 (USA), phone: 301-286-1412, fax: 301-2864699, email: martha.v.obryan@nasa.gov.

Kenneth A. LaBel, Jonathan A. Pellish, Jean-Marie Lauenstein, Dakai Chen, Cheryl Marshall, Megan C. Casey, Anthony B. Sanders, Raymond L. Ladbury, and Alvin J. Butte are with NASA/GSFC, Code 561.4, Greenbelt, MD 20771 (USA), email: kenneth.a.label@nasa.gov, jonathan.a.pellish anasa.gov, jean.m.lauenstein@anasa.gov, Dakai.Chen-1 annasa.gov, cheryl.j.marshall@nasa.gov, megan.c.casey@nasa.gov, Anthony.B.Sanders a nasa.gov, raymond.l.ladbury (4) nasa.gov, and Alvin.J.Boutte (anasa.gov.

Robert A. Gigliuto, Hak S. Kim, Anthony M. Phan, Melanie Berg, and Ted Wilcox are with MEI Technologies, Inc., work performed for NASAVGSFC, Code 561.4, Greenbelt, MD 20771 (USA), email: Hak.S.Kimannasa.gov, Anthony.M.Phananasa.gov, Melanie.D.Berg@nasa.gov, and Ted.Wilcox ânasa.gov.

Timothy R. Oldham is with Perot Systems Government Services, Inc., work performed for NASAJGSFC, Code 561.4, Greenbelt. MD 20771 (USA), email: timothy.r. oldham a nasagov.

Paul W. Marshall is a Consultant, email: pwmarshall@aol.com.

Paul L. Musil and Greg A. Overend are with M.S. Kennedy Corp., Liverpool, NY 13088 (USA), email: p.musil@mskennedy.com, g.overend@mskennedy.com.

\section{TEST TECHNIQUES AND SETUP}

\section{A. Test Facilities}

All SEE tests were performed between March 2011 and February 2012. Heavy ion experiments were conducted at Lawrence Berkeley National Laboratory (LBNL) [3], and at Texas A\&M University Cyclotron (TAMU) [4]. Both of these facilities are suitable for providing a variety of ions over a range of energies for testing. The devices under test (DUTs) were irradiated with heavy ions having linear energy transfers (LETs) ranging from 0.59 to $120 \mathrm{MeV} \cdot \mathrm{cm}^{2} / \mathrm{mg}$. Fluxes ranged from $1 \times 10^{2}$ to $1 \times 10^{7}$ particles $/ \mathrm{cm}^{2} / \mathrm{s}$, depending on device sensitivity. Representative ions used are listed in Table I. This table is truncated in an attempt to keep this summary submission within the page limitations. LETs between the values listed were obtained by changing the angle of incidence of the ion beam with respect to the DUT, thus changing the path length of the ion through the DUT and the "effective LET" of the ion [5]. Energies and LETs available varied slightly from one test date to another.

Proton SEE tests were performed at three facilities: the University of California at Davis (UCD) Crocker Nuclear Laboratory (CNL) [6], the Indiana University Cyclotron Facility (IUCF) [7], and at a $2 \mathrm{MeV}$ Van de Graaff (VdG) particle accelerator. Proton test energies incident on the DUT are listed in Table II.

Laser SEE tests were performed at the pulsed laser facility at the Naval Research Laboratory (NRL) [8] [9]. The laser light had a wavelength of $590 \mathrm{~nm}$ resulting in a skin depth (depth at which the light intensity decreased to $1 / \mathrm{e}$ - or about $37 \%$ - of its intensity at the surface) of $2 \mu \mathrm{m}$. A nominal pulse rate of $1 \mathrm{kHz}$ was utilized.

TABLE I: HEAVy ION TEST FACILITIES AND TEST HEAVy IONS

\begin{tabular}{|c|c|c|c|c|}
\hline Facility & Ion & $\begin{array}{c}\text { Energy } \\
(\mathrm{MeV})\end{array}$ & $\begin{array}{c}\text { Surface } \\
\text { LET In SI } \\
\left(\mathrm{MeV} \cdot \mathrm{cm}^{2} / \mathrm{mg}\right) \\
\text { (Normal Incidence) }\end{array}$ & $\begin{array}{c}\text { Range in } \\
\text { Si }(\mu \mathrm{m})\end{array}$ \\
\hline \multirow{4}{*}{ LBNL } & ${ }^{18} \mathrm{O}$ & 184 & 2.2 & 227 \\
\hline & ${ }^{22} \mathrm{Ne}$ & 216 & 3.5 & 175 \\
\hline & ${ }^{65} \mathrm{Cu}$ & 659 & 21 & 110 \\
\hline & \multicolumn{4}{|c|}{$10 \mathrm{MeV}$ per AMU tune } \\
\hline \multirow{4}{*}{ TAMU } & ${ }^{109} \mathrm{Ag}$ & 1634 & 39 & 156 \\
\hline & ${ }^{129} \mathrm{Xe}$ & 1934 & 47 & 156 \\
\hline & ${ }^{181} \mathrm{Ta}$ & 2076 & 77 & 110 \\
\hline & \multicolumn{4}{|c|}{$15 \mathrm{MeV}$ per AMU tune } \\
\hline
\end{tabular}


TABLE II: PROTON TEST FACILITIES

University of California at Davis (UCD) Crocker Nuclear Laboratory (CNL), energy tunes ranged from 6.5 to $63 \mathrm{MeV}$, flux ranged from $8 \times 10^{7}$ to $1 \times 10^{9}$ particles $/ \mathrm{cm}^{2} / \mathrm{s}$.

Indiana University Cyclotron Facility (IUCF), energy ranged from 63 to $198 \mathrm{MeV}$, flux ranged from $5 \times 10^{3}$ to $3 \times 10^{9}$ particles $/ \mathrm{cm}^{2} / \mathrm{s}$.

TABLE III: LASER TEST FACILITY

Naval Research Laboratory (NRL) Pulsed Laser SEE Test Facility

Laser: $590 \mathrm{~nm}, 1$ ps pulse width, beam spot size $\sim 1.2 \mu \mathrm{m}$

\section{B. Test Method}

Unless otherwise noted, all tests were performed at room temperature and with nominal power supply voltages. We recognize that high-temperature and worst-case power supply conditions are recommended for single event latchup (SEL) device qualification.

\section{1) SEE Testing - Heavy Ion:}

Depending on the DUT and the test objectives, one or more of three SEE test methods were typically used:

Dynamic - the DUT was exercised continually while being exposed to the beam. The events and/or bit errors were counted, generally by comparing the DUT output to an unirradiated reference device or other expected output (Golden chip or virtual Golden chip methods) [10]. In some cases, the effects of clock speed or device operating modes were investigated. Results of such tests should be applied with caution due to the application-specific nature of the results.

Static - the DUT was loaded prior to irradiation; data were retrieved and errors were counted after irradiation.

Biased - the DUT was biased and clocked while power consumption was monitored for SEL or other destructive effects. In most SEL tests, functionality was also monitored.

In SEE experiments, DUTs were monitored for soft errors, such as SEUs and for hard errors, such as single event gate rupture (SEGR). Detailed descriptions of the types of errors observed are noted in the individual test reports [11],[12].

SET testing was performed using a high-speed oscilloscope controlled via Labview@ Individual criteria for SETs are specific to the device being tested and application. Please see the individual test reports for details [11].

Heavy ion SEE sensitivity experiments include measurement of the Linear Energy Transfer threshold $\left(\operatorname{LET}_{t h}\right)$ and cross section at the maximum measured LET. The LET th is defined as the maximum LET value at which no effect was observed at an effective fluence of $1 \times 10^{7}$ particles $/ \mathrm{cm}^{2}$. In the case where events are observed at the smallest LET tested, $\mathrm{LET}_{\text {th }}$ will either be reported as less than the lowest measured LET or determined approximately as the LET $_{\text {th }}$ parameter from a Weibull fit. In the case of SEGR experiments, measurements are made of the SEGR threshold $V_{d s}$ as a function of LET at a fixed $\mathrm{V}_{\mathrm{gs}}$.

2) SEE Testing - Proton

Proton SEE tests were performed in a manner similar to heavy ion exposures. However, because protons can cause SEE via indirect ionization by recoil particles, results are usually parameterized in terms of proton energy rather than
LET. Because such proton-induced nuclear interactions are rare, proton tests also feature higher cumulative fluences and particle flux rates than heavy ion experiments.

\section{3) Pulsed Laser Facility Testing}

The DUT was mounted on an $\mathrm{X}-\mathrm{Y}-\mathrm{Z}$ stage in front of a $100 \mathrm{x}$ lens that produced a spot diameter of about $1.2 \mu \mathrm{m}$ at full-width half-maximum (FWHM). The X-Y-Z stage can be moved in steps of $0.1 \mu \mathrm{m}$ for accurate positioning of SEU sensitive regions in front of the focused beam. An illuminator together with a charge coupled device camera and monitor were used to image the area of interest, thereby facilitating accurate positioning of the device in the beam. The pulse energy was varied in a continuous manner using a polarizer/half-waveplate combination and the energy was monitored by splitting off a portion of the beam and directing it at a calibrated energy meter.

\section{TEST RESULTS OVERVIEW}

Abbreviations and conventions are listed in Table IV. Table V contains a subset of the Principal Investigators. SEE results are summarized in Table VI. All tables are truncated in an effort to keep this summary submission within the page limitations. Also, some formatting modifications (i.e. smaller font sizes) were used in these tables in order to keep this summary submission within the page limitations. Unless otherwise noted, all LETs are in $\mathrm{MeV} \cdot \mathrm{cm}^{2} / \mathrm{mg}$ and all cross sections are in $\mathrm{cm}^{2} /$ device. All SEL tests are performed at a fluence of $1 \times 10^{-7}$ particles $/ \mathrm{cm}^{2}$ unless otherwise noted.

TABLE IV: ABBREVLATIONS AND CONVENTIONS

LET $=$ linear energy transfer $\left(\mathrm{MeV} \cdot \mathrm{cm}^{2} / \mathrm{mg}\right)$

$\mathrm{LET}_{\text {th }}=$ linear energy transfer threshold (the maximum LET value at which no effect was gbserved at an effective fluence of $1 \times 10^{7}$ particles $/ \mathrm{cm}^{2}-$ in $\mathrm{MeV} \cdot \mathrm{cm}^{2} / \mathrm{mg}$ )

$<=$ SEE observed at lowest tested LET

$>=$ no SEE observed at highest tested LET

$\sigma=$ cross section $\left(\mathrm{cm}^{2} /\right.$ device, unless specified as $\left.\mathrm{cm}^{2} / \mathrm{bit}\right)$

$\sigma_{\max }$ measured $=$ cross section at maximum measured LET ( $\mathrm{cm}^{2} /$ device, unless specified as $\mathrm{cm}^{2} /$ bit)

$\mathrm{BiCMOS}=$ bipolar complementary metal oxide semiconductor

CMOS = complementary metal oxide semiconductor

DUT $=$ device under test

$\mathrm{H}=$ heavy ion test

$\mathrm{L}=$ laser test

LBNL = Lawrence Berkeley National Laboratory

LDC $=$ lot date code

$\mathrm{NRL}=$ Naval Research Laboratory

$\mathrm{P}=$ proton test (SEE)

$\mathrm{PI}=$ principal investigator

$\mathrm{pJ}=$ petajoules

SEE = single event effect

SEFI $=$ single event functional interrupt

SEGR = single event gate rupture

$\mathrm{SEL}=$ single event latchup

$\mathrm{SET}=$ single event transient

$\mathrm{SEU}=$ single event upset

TABLE V: LIST OF PRNCIPAL INVESTIGATORS

\begin{tabular}{lc}
\hline \multicolumn{1}{c}{ Principal Investigator (PI) } & Abbreviation \\
\hline Megan Casey & MB \\
Dakai Chen & DC \\
Bob Gigliuto & BG \\
\hline
\end{tabular}


TABLE VI: SUMMARY OF SEE TEST RESULTS

As in past workshop compendia of GSFC test results, this table will contain summaries for over 30 parts. In an effort to attempt to keep this summary submission within the page limitations, only two parts are summarized in the table below.

\begin{tabular}{|c|c|c|c|c|c|c|c|c|}
\hline Part Number & Manufacturer & LDC & Device Function & $\begin{array}{l}\text { Tech- } \\
\text { nology }\end{array}$ & $\begin{array}{c}\text { Particle: (Facility/Date) } \\
\text { P.l. }\end{array}$ & $\begin{array}{l}\text { Test Results LET In MeV॰cm }{ }^{2} / \mathrm{mg} \sigma \text { In } \\
\mathrm{cm}^{2} / \text { device, unless otherwise } \\
\text { specified }\end{array}$ & 층욜 & 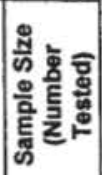 \\
\hline $\begin{array}{l}\text { MSK5059RH } \\
\text {. }\end{array}$ & M. S. Kennedy & $\begin{array}{c}\text { MSK } \\
5059 R H G \\
\text { Be0 } \\
51651 \text { USA }\end{array}$ & $\begin{array}{l}\text { Step down } \\
\text { switching } \\
\text { regulator }\end{array}$ & BiCMOS & L: (NRL11AUG) DC & $\begin{array}{l}\text { L: Output voltage dropouts were } \\
\text { observed on one location of DUT } \\
\text { for various output loads ranging } \\
\text { from } 0.2 \text { to } 4 \mathrm{~A} \text {. } \\
\text { The laser energy threshold for the } \\
\text { dropout events were } ~-55 \text { to } \\
110 \text { pJ. }[13]\end{array}$ & $\begin{array}{l}1.8 \text { and } \\
3.3 \mathrm{~V}\end{array}$ & 1 \\
\hline MTR28515 & Crane/ Interpoint & $1119 \mathrm{~T}$ & \begin{tabular}{|c|} 
Triple Channel \\
DC/DC Converter \\
\end{tabular} & Hybrid & H: (TAMU11Oct) MC & $\begin{array}{l}\text { H: SEUSEGR/SEB LET in }<51.5 ; \\
\text { SETs were observed. }\end{array}$ & $\begin{array}{l}+5 \mathrm{~V} \text { and } \\
+1.15 \mathrm{~V}\end{array}$ & 3 \\
\hline
\end{tabular}

\section{V. TEST RESUlts AND DisCusSiON}

As in our past workshop compendia of NASA Goddard Space Flight Center (GSFC) test results, each DUT has a detailed test report available online at http://radhome.gsfc. nasa.gov [11] describing the test method, SEE conditions/ parameters, test results, and graphs of data.

Due to page limitations this section contains two featured part, however, the final data workshop submission will contain several summaries of testing performed on a selection of featured parts.

\section{A. Crane Electronics MTR28515 DC/DC Converter}

The MTR28515 is a triple-channel DC/DC converter that offers $30 \mathrm{~W}$ of output power manufactured by Crane Electronics. The part uses a $28 \mathrm{~V}$ input voltage, and supplies 5 $\mathrm{V}$ and $\pm 15 \mathrm{~V}$ output voltages. This study was undertaken to identify sensitivities to SET and destructive failures.

The MTR28515 tests were conducted in air at TAMU using three different ion species ( $\mathrm{Ag}, \mathrm{Xe}$, and $\mathrm{Ta}$ ) with LETs of 42 , 52 , and $77 \mathrm{MeV} \cdot \mathrm{cm}^{2} / \mathrm{mg}$, and three loading conditions. For all loading conditions, the output current on the $-15 \mathrm{~V}$ channel was kept at a constant $10 \%$, or $0.4 \mathrm{~A}$. As for the $5 \mathrm{~V}$ and +15 $\mathrm{V}$ channels, the output currents were varied simultaneously between $0.4 \mathrm{~A}, 2.0 \mathrm{~A}$, and $3.4 \mathrm{~A}$, which equates to $10 \%, 50 \%$, and $85 \%$ of the maximum load. A total of three parts were irradiated, and because of the physical size of the parts, each part was irradiated in two positions called position 1 and position 2 for simplicity. Fig. 1 shows a photograph of the delidded MTR28515. The application boards were attached to metal plates to facilitate conductive heat sinking, as well as being actively cooled by a chiller.

Regular voltage spikes were observed, with magnitudes of 600 to $700 \mathrm{mV}$ that lasted for approximately $200 \mathrm{~ns}$. However, these spikes were evident when the part was in the cave without the beam turned on, which indicates that these signatures originated from sources external to the device and test board, and likely were the result of noise associated with the accelerator electronics. When the ion beam was turned on, the oscilloscope triggered on larger voltage spikes with amplitudes of $1.3 \mathrm{~V}$ and durations of roughly $350 \mathrm{~ns}$. However, after further analysis, it became clear that the actual transients were much longer and the oscilloscope only captured $5 \mu$ s (with an amplitude of $150 \mathrm{mV}$ ). Because the oscilloscope trigger was not set to capture the small amplitude, long duration transients, it is impossible to know if all transients were captured, and therefore the transient crosssection cannot be calculated. The captured transient signatures were similar across loading conditions and LETs and were only seen when position 2 was irradiated. Fig. 2 shows an example of SETs captured at two different output loads.

More important than the transients though was the observation of a destructive failure that occurred at a LET of $77 \mathrm{MeV} \cdot \mathrm{cm}^{2} / \mathrm{mg}$ when the part was biased at $35 \mathrm{~V}$ on the input with $50 \%$ load conditions; position 2 was being irradiated at the time of the failure. The input bias current had stayed constant at $0.5 \mathrm{~A}$, but after a fluence of $1.3 \times 10^{6}$ particles $/ \mathrm{cm}^{2}$, the current immediately jumped to $3.3 \mathrm{~A}$ (this value was chosen as the limiting current in the test set-up) and the part remained non-functioning even after power cycle). The MTR28515 had previously passed for all loading conditions and ion species when the input voltage was $28 \mathrm{~V}$. It also passed for an input voltage of $35 \mathrm{~V}$ for all loading conditions when irradiated with $\mathrm{Ag}$ and $\mathrm{Xe}$, as well as with $\mathrm{Ta}$ when the load was $10 \%$ of maximum rated current. Because the part failed at $50 \%$ load, it was not tested with $\mathrm{Ta}$ and an input voltage of $35 \mathrm{~V}$ with a load of $85 \%$ so as not to destroy an additional part. After failure analysis, it was determined that the destructive failure was single-event burnout in one of the power diodes (see Fig. 3).

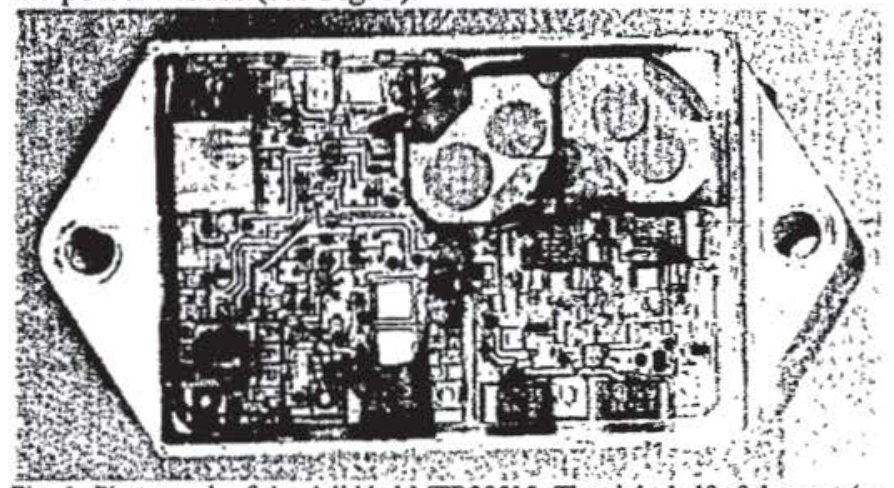

Fig. 1. Photograph of the delidded MTR28515. The right half of the part (as shown in this photograph) was called position 1 , and the left half was called position 2 . Transients were only seen when position 2 was irradiated. 


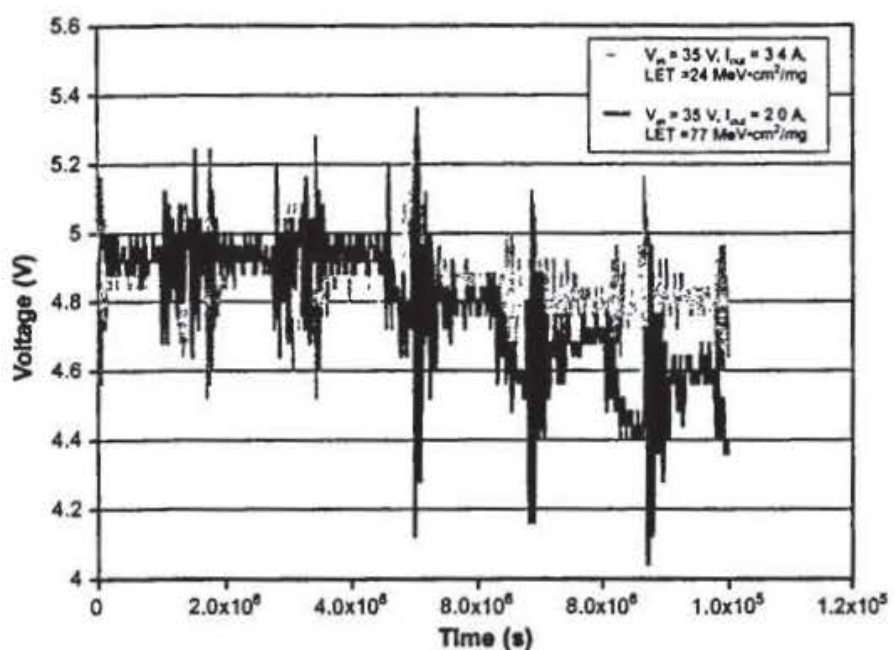

Fig. 2. SETs at input voltages of $35 \mathrm{~V}$, and output loads of $50 \%$ and $85 \%$ of maximum (2.0 A and $3.4 \mathrm{~A})$.

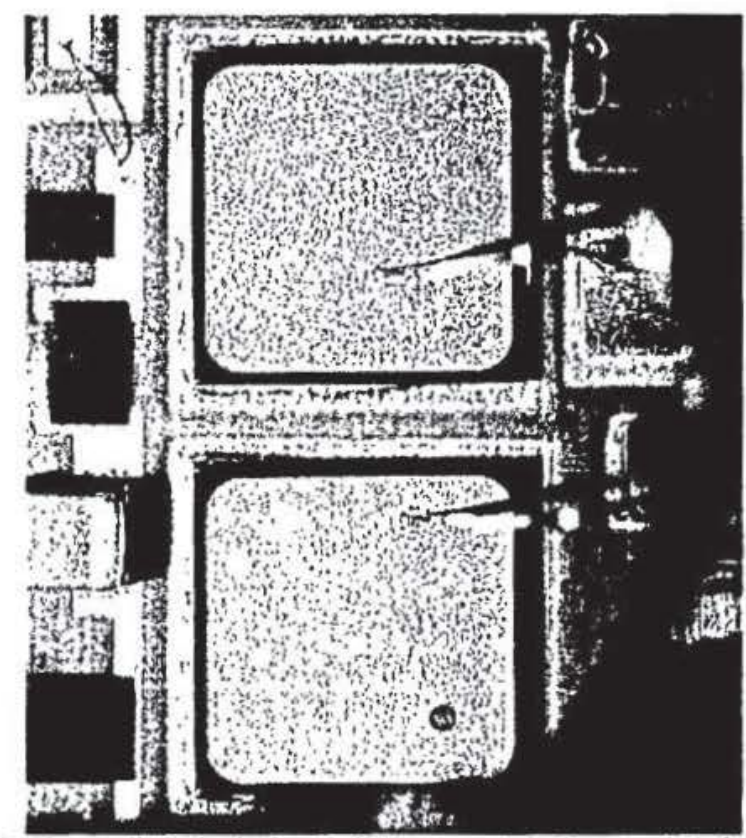

Fig. 3. The small dot in the lower right corner of the bottom diode is due to meited metal from the single-event burnout.

\section{B. International Rectifier M3G2804R513R5T DC/DC Converter}

A customized M3G2804R513R5T DC-DC Converter from International Rectifier was tested for SEE at TAMU. Fig. 4 shows a picture of the DUT with exposure zones annotated. The device construction was complicated by commercial devices not intended for flight. SEE were observed and documented. A detailed summary of test results will be included in the final data workshop submission pending programmatic approval.

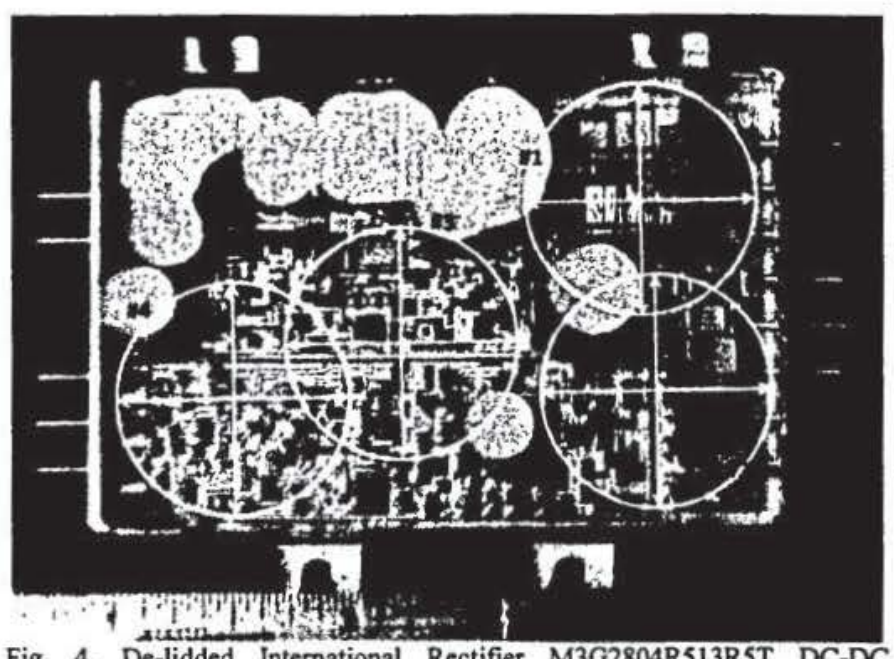

Fig. 4. De-lidded International Rectifier M3G2804R513R5T DC-DC Converter with exposure zones annotated.

\section{SUMMARY}

We have presented current data from SEE testing on a variety of mainly commercial devices. It is the authors' recommendation that this data be used with caution. We also highly recommend that lot testing be performed on any suspect or commercial device.

\section{REFERENCES}

[1] Kenneth A. LaBel, Lewis M. Cohn, and Ray Ladbury,"Are Current SEE Test Procedures Adequate for Modern Devices and Electronics Technologies?," http://radhome. gsfc. nasa. gov/ radhome/ papers/ HEART08 LaBel.pdf

[2] Donna J. Cochran, Dakai Chen, Timothy Oldham, Hak Kim, Stephen Buchner, Kenneth A. LaBel, Jonathan Pellish, Martin A. Carts, Martha V. O'Bryan, and Anthony B. Sanders, " Compendium of Total Ionizing Dose and Displacement Damage for Candidate Spacecraft Electronics for NASA," submitted for publication in IEEE Radiation Effects Data Workshop, Jul. 2012.

[3] Michael B. Johnson, Berkeley Lawrence' Berkeley National Laboratory (LBNL), 88-Inch Cyclotron Accelerator, Accelerator Space Effects (BASE) Facility http://cyclotron.lbl.gov.

[4] B. Hyman, "Texas A\&M University Cyclotron Institute, K500 Superconducting Cyclotron Facility," http://cyclotron.tamu.edu/ facilities.htm, Jul. 2003.

[5] W.J. Stapor, "Single-Event Effects Qualification," IEEE NSREC95 Short Course, sec. II, pp 1-68, Jul. 1995.

[6] C. M. Castaneda, University of California at Davis (UCD) "Crocker Nuclear Laboratory (CNL) Radiation Effects Measurement and Test Facility," IEEE NSREC01 Data Workshop, pp. 77-81, Jul. 2001.

[7] C. C. Foster, S. L. Casey, P. Miesle, N. Sifri, A. H. Skees, K. M. Murray, "Opportunities for Single Event and Other Radiation Effects Testing and Research at the Indiana University Cyclotron Facility, "IEEE NSREC96 Data Workshop, pp. 84-87, Jul. 1996.

[8] J. S. Melinger, S. Buchner, D. McMorrow, T. R. Weatherford, A. B. Campbell, and $\mathrm{H}$. Eisen, "Critical evaluation of the pulsed laser method for single event effects testing and fundamental studies," IEEE Trans. Nucl. Sci., vol 41, pp. 2574-2584, Dec. 1994.

[9] D. McMorrow, J. S. Melinger, and S. Buchner, "Application of a Pulsed Laser for Evaluation and Optimization of SEU-Hard Designs," IEEE Trans Nucl. Sci., vol 47, no. 3, pp. 559-565, Jun. 2000.

[10] R. Koga and W. A. Kolasinski, "Heavy lon-Induced Single Event Upsets of Microcircuits; A Summary of the Aerospace Corporation Test Data," IEEE Trans. Nucl. Sci., Vol. 31, No. 6, pp. 1190-1195, Dec. 1984.

[11] NASAGGFC Radiation Effects and Analysis home page, http://radhome.gsfc.nasa.gov

[12] NASA Electronic Parts and Packaging (NEPP) web site, http://nepp.nasa.gov/.

[13] Dakai Chen, and Ted Wilcox, "Pulsed-laser Test Report of the MSK5059RH Sivitching Regulator," http://radhome.gsfc.nasa.gov/ radhome/ papers/ NRL082411_MSK5059RH.pdf, Aug. 2011. 